\title{
Modelling the Marangoni convection in laser heat treatment
}

\author{
J.-M. Drezet ${ }^{1}$, S. Pellerin ${ }^{1}$, C. Bezençon ${ }^{2}$ and S. Mokadem ${ }^{2}$ \\ ${ }^{1}$ Calcom ESI SA, Parc Scientifique, 1015 Lausanne, Switzerland \\ e-mail: www. calcom.ch \\ ${ }^{2}$ Laboratoire de Métallurgie Physique, EPF-Lausanne, 1015 Lausanne, Switzerland \\ e-mail: www.epfl.ch/lsmx
}

\begin{abstract}
Epitaxial Laser Metal Forming (E-LMF) consists in impinging a jet of metallic powder onto a molten pool formed by controlled laser heating and thereby, generating epitaxially a single crystal deposit onto the damaged component. This new technique aims to be used for the repair and reshape single crystal gas turbine components. Because of the very localised melting pool, the high temperature gradients produced during the process must be carefully controlled in order to avoid both the columnar-to-equiaxed transition (CET) and the appearance of hot tears. To this end, heat flow modelling is required to establish the relationship between process parameters such as laser power, beam diameter and scanning speed, and the local solidification conditions. When modelling the heat transfer within the sample, it is necessary to include the liquid flow pattern generated by the surface tension driven convection known as the Marangoni effect. Indeed, the fluid flow in the liquid pool dictates the shape of the traces as shown by the measurements carried out at EPF-Lausanne in re-melting experiments. A three dimensional (3D) model is implemented in the finite element software calcosoft $t^{\circledR}$ in order to model the development of the fluid convection within the liquid pool. It is shown that the velocities due to natural convection are of the order of $1 \mathrm{~mm} / \mathrm{sec}$ whereas Marangoni convection produces velocities of the order of $1 \mathrm{~m} / \mathrm{sec}$. Moreover, at low scanning speeds, the liquid pool becomes larger than the beam diameter and the development of Marangoni eddies leads to a widening and deepening of the pool. The local solidification conditions such as the thermal gradient and the solidification speed can be extracted at both the solidus and liquidus temperatures to assess the risk of CET and hot cracking.
\end{abstract}

\section{INTRODUCTION}

Epitaxial Laser Metal Forming (E-LMF) [1] is a new technique to repair and reshape single crystal gas turbine components. It consists in impinging a jet of metallic powder onto a molten pool formed by controlled laser heating and thereby, generating epitaxially a single crystal deposit onto the damaged component. This method is characterised by a high precision and very local treatment in which powder is injected into the melt pool produced by the laser beam tracking over the surface of the workpiece. During the process, a protective gas, such as Argon, is used to reduce oxidation. As a thin layer of the substrate is melted, a perfect interface, i.e. metallurgical bonding, is achieved. If nucleation is avoided, solidification occurs epitaxially onto the substrate in a columnar growth regime and a single crystal wall is deposited onto a single crystal substrate, as shown in Fig. 1.

Because of the very localised laser heating, high temperature gradients are produced during the process. This leads to high residual stresses and deformations, which can affect the service behaviour of the work piece [2]. On the other hand, the temperature gradients must be high enough to avoid the columnar-to-equiaxed transition (CET) [3] but carefully controlled not to initiate hot tears [4]. To study these two aspects, it is necessary to get the solidification parameters such as the thermal gradient $\mathrm{G}$ and the growth rate $\mathrm{V}$ at both the solidus and liquidus isotherms. So far, most of the models were based on 


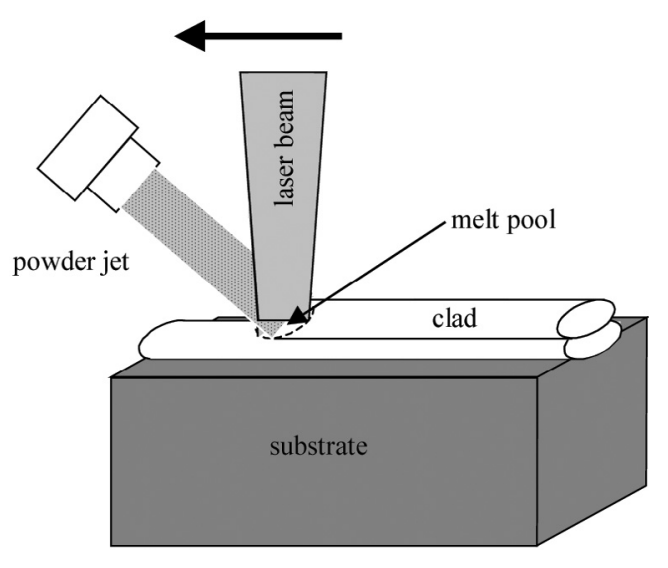

Figure 1. Illustration of the Epitaxial Laser Metal Forming process. Powder is injected into the melt pool produced by a laser beam tracking over the surface of a single crystal substrate.
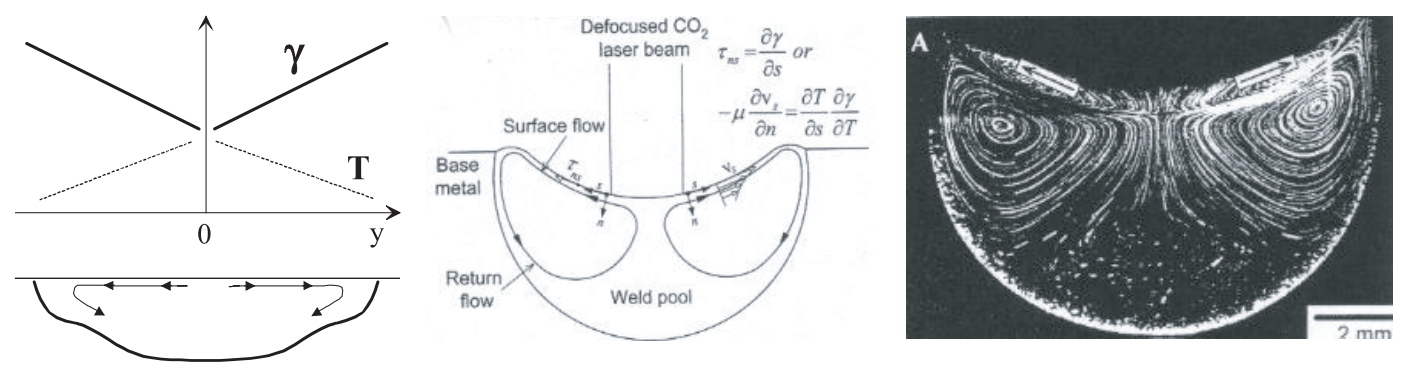

Figure 2. Illustration of the Marangoni effect: a) temperature dependence of the surface tension, b) Marangoni eddies in a weld pool [8] and c) observation of these eddies in a transparent alloy [8].

the analytical solution provided by the Rosenthal point source model [5] or on heat flow modelling with an increased thermal conductivity in the liquid phase to take into account the heat transport [6,7].

Marangoni convection, also called surface-tension-driven convection or thermocapillary convection, is well known in welding: it can have a dramatic effect on the penetration depth of the resultant weld pool [8]. Marangoni convection in a laser remelted pool is illustrated in Fig. 2 : fluid flow near the pool surface is outward, with the maximum velocity located at and tangent to the pool surface. The outwardpointing shear stress at the pool surface, $\overrightarrow{\tau_{\mathrm{nS}}}=-\mu \frac{\partial \mathrm{V}_{\mathrm{S}}}{\partial \mathrm{n}}$, is induced by the surface-tension gradients along the pool surface $\partial \gamma / \partial \mathrm{s}$ where $\gamma$ is the surface tension; $\mathrm{s}$ and $\mathrm{n}$ denotes the tangent and normal direction to the surface, respectively. These surface-tension gradients are induced both by the temperature gradients along the pool surface $\partial \mathrm{T} / \partial \mathrm{s}<0$ and the temperature-dependence of $\gamma, \partial \gamma / \partial \mathrm{T}<0$, which is the case for most materials. The fluid is then pulled along the surface from the centre where temperature is high and the surface tension is low, to the edge where temperature is low and surface tension is high. The visualisation of the outward flow along the pool surface and the return flow in the interior of the pool is presented in Fig. 2 for a transparent material $\mathrm{NaNO}_{3}$ [8]. Surface tension gradient could also results from solute gradient but this effect is neglected here.

The difficulty in modelling the heat transfer within the work-piece in laser treatments comes from the necessity to include the liquid flow pattern generated by the surface tension driven convection. Indeed, the fluid flow in the liquid pool dictates the shape of the traces and largely influence the thermal field close to the mushy zone. For sake of simplicity, experiments were carried out using laser surface remelting. The experimental results are reported in section II. The FEM fluid and thermal flow model built in calcosoft ${ }^{\circledR}[9]$ is presented in section III. Finally, the results are discussed in section IV. 


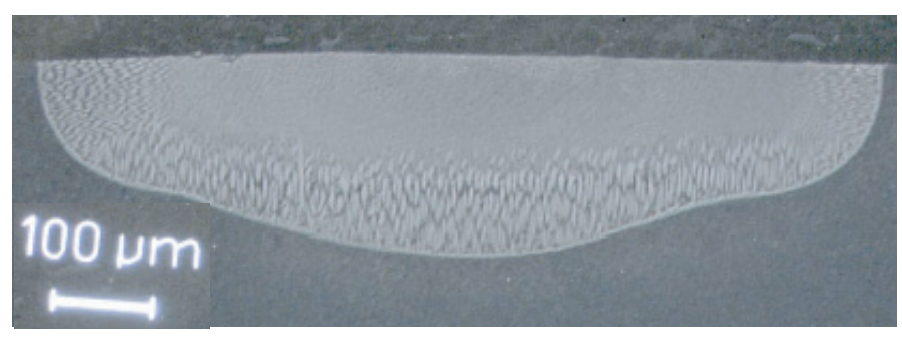

Figure 3. Transverse section of the laser trace $\left(\mathrm{P}=680 \mathrm{~W}, \mathrm{D}_{b}=0.76 \mathrm{~mm}\right.$, $\left.\mathrm{V}_{b}=10 \mathrm{~mm} / \mathrm{sec}, \tau=0.06 \mathrm{~s}\right)$.
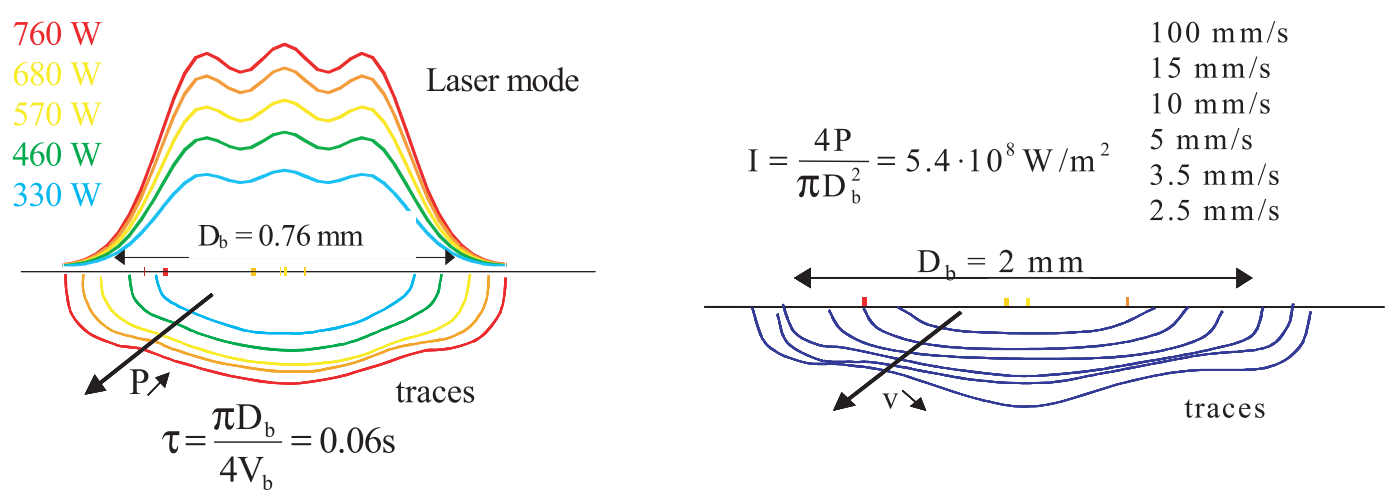

Figure 4. Measured re-melting traces (liquidus lines, neglecting the undercooling of about $20^{\circ} \mathrm{C}$ ) for : left, a constant interaction time, $\tau \mathrm{s}$ with laser mode on top [11], and right, for a constant beam intensity, I [10].

\section{EXPERIMENTAL OBSERVATIONS}

In order to study the influence of the Marangoni convection in the liquid pool, re-melting experiments were carried out on CMSX4 samples using a $1.5 \mathrm{~kW} \mathrm{CO}_{2}$ continuous wave laser with a bimodal intensity profile close to a top-hat. One single laser trace was made over the sample and transverse section was obtained by cutting the sample and etching. A typical micrography is shown in Fig. 3. Experiments were conducted under two configurations, the main process parameters being the laser power $\mathrm{P}$, the beam diameter $\mathrm{D}_{b}$ and the scanning speed $\mathrm{V}_{b}$. The first series of experiments consisted in keeping the interaction time, defined by $\tau=\pi \mathrm{D}_{b} \cdot / 4 \mathrm{~V}_{b}$, constant and varying the laser power $\mathrm{P}$ from $330 \mathrm{~W}$ to $760 \mathrm{~W}$ [10]. In the second series, the beam intensity defined by $\mathrm{I}=4 \mathrm{P} / \pi \mathrm{D}_{b}^{2}$, was kept constant and the scanning speed $\mathrm{V}_{b}$ was varied from $2,5 \mathrm{~mm} / \mathrm{sec}$ to $100 \mathrm{~mm} / \mathrm{sec}$ [11].

The laser traces obtained for these two configurations are presented in Fig. 4 together with the laser beam mode made out of three gaussian distributions. When the width of the laser trace is lower than the beam diameter, the shape of the trace is similar to that of an half ellipse, as already reported in literature [6]. But when the liquid pool gets larger than the beam diameter, Marangoni eddies appear at the periphery of the laser pool owing to the large surface thermal gradients. This convection largely affect the traces by widening them and/or deepening them at their centre. This change in the shape of the traces is visible under both configurations, at high power when $\tau$ is kept constant and at low velocities when I is constant. These experiments clearly demonstrate the importance of the Marangoni convection when describing the shape of the laser trace. 


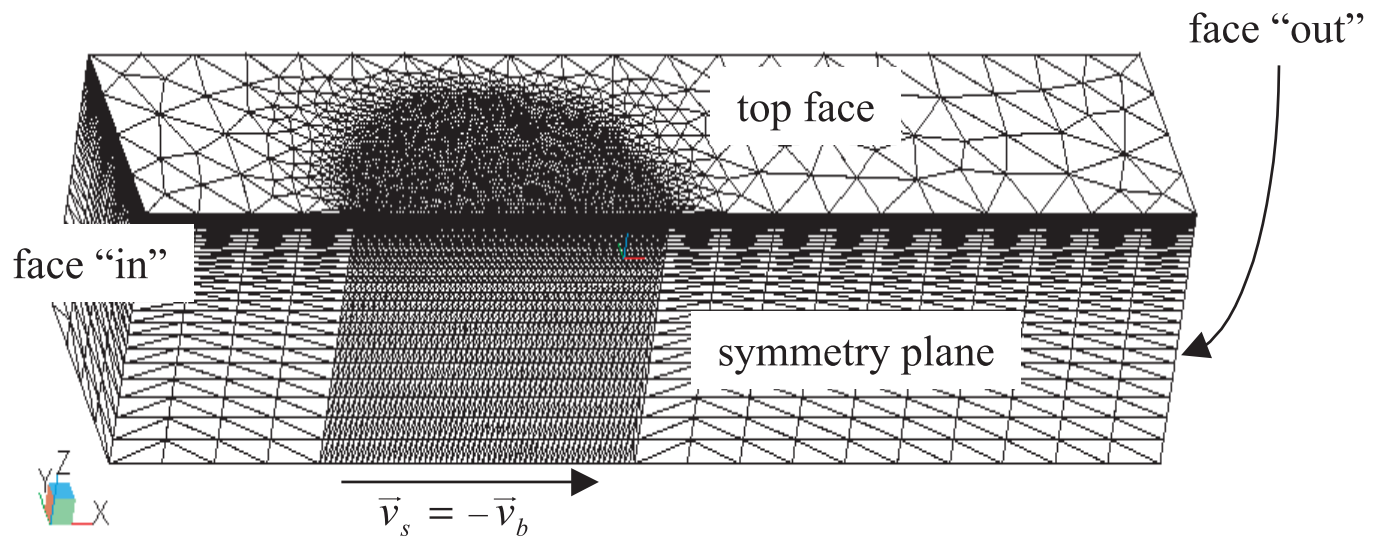

Figure 5. FEM mesh with solid velocity and references used for the computation.

\section{FE MODELLING}

A three dimensional (3D) finite element model was implemented in the finite element software calcosoft ${ }^{\circledR}$ [6] in order to model the development of the fluid convection within the liquid pool and to assess the influence of the Marangoni convection. The momentum equation is solved together with the heat conservation within a work piece, $4 \mathrm{~mm}$ in width, $2 \mathrm{~mm}$ in thickness and $10 \mathrm{~mm}$ in length. Latent heat associated with solidification is taken into account by an enthalpy formulation and the fluid flow within the solidification interval is solved using the Darcy equation and the Carman-Kozeny approximation for the permeability [6]. Fig. 5. shows the mesh used for the computation. Owing to symmetry reasons, only one half of the work piece is modelled. As we are interested only in the steady state development of the fluid and heat flow, the description adopted here is an eulerian description assuming that the material is transported along the $\mathrm{x}$ axis under the fixed laser beam at a given scanning speed opposite to the laser beam velocity, $\vec{v}_{s}=-\vec{v}_{b}$. The co-ordinates $\left(\mathrm{x}_{0}, \mathrm{y}_{0}, \mathrm{z}_{0}\right)$ of the centre of the laser beam are $(3.2 \mathrm{~mm}, 0.0$, $2 \mathrm{~mm}$ ) in the reference frame. The mesh is made out of 69'000 nodes and 389'520 tetrahedras. The region under the laser beam presents a much higher mesh density.

\subsection{Initial conditions}

The initial velocity is set to the solid transport velocity, $\vec{v}_{s}=-\vec{v}_{b}$, and the initial temperature distribution is given by the Rosenthal equation for semi-infinite sample [5], assuming a point heat source located at the centre of the laser beam :

$$
\left.\mathrm{T}(\mathrm{x}, \mathrm{y}, \mathrm{z}, \mathrm{t}=0)=\mathrm{T}_{0}+\frac{\beta \mathrm{P}}{2 \pi \mathrm{kr}} \exp \left(-\frac{\mathrm{v}_{\mathrm{b}}\left(\mathrm{r}+\mathrm{x}-\mathrm{x}_{\mathrm{o}}\right)}{2 \alpha}\right) \text { withr }=\sqrt{\left(x-x_{0}\right.}\right)^{2}+\mathrm{y}^{2}+\left(\mathrm{z}-\mathrm{z}_{0}\right)^{2}
$$

where $\beta$ is the absorption coefficient (16\%), $\mathrm{P}$ the power of the laser $(1700 \mathrm{~W}), \mathrm{k}$ the mean thermal conductivity of the CMSX4 and $\alpha$ its average thermal diffusivity. $\mathrm{T}_{o}$, is taken as $20^{\circ} \mathrm{C}$. Note that the Rosenthal equation is used here simply as an initial condition; the computations will be carried out without the Rosenthal assumptions which are no latent heat, constant properties, semi-infinite domain and no liquid convection. 


\subsection{Boundary conditions}

On the top surface, the thermal boundary conditions corresponds to an imposed heat flux:

$$
\mathrm{q}=\frac{\beta \mathrm{P}}{2 \pi} \sum_{\mathrm{i}}{\frac{\mathrm{b}_{\mathrm{i}}}{\sigma_{\mathrm{i}}}}^{2} \exp \left(-\frac{\left(\mathrm{x}-\mathrm{x}_{0}\right)^{2}+\mathrm{y}^{2}}{2 \sigma_{\mathrm{i}}^{2}}\right)-\mathrm{h}\left(\mathrm{T}_{\mathrm{s}}-\mathrm{T}_{\mathrm{ex}}\right)-\varepsilon \sigma\left(\mathrm{T}_{\mathrm{s}}^{4}-\mathrm{T}_{\text {ex }}^{4}\right), \sigma_{\mathrm{i}}=\mathrm{a}_{\mathrm{i}} \mathrm{D} / 2
$$

The laser heat distribution corresponds to the sum of three gaussian distributions (coefficients $\mathrm{b}_{i}$ and $\mathrm{a}_{i}$ ) centred under the laser beam (cf. Fig. 4): the extension of the laser heat input is given by the beam diameter $\mathrm{D}(\mathrm{D}=2 \mathrm{~mm})$. The heat transfer coefficient $\mathrm{h}$ traduces the cooling associated with the use of a laminar flow of protective gas; its value is set to $200 \mathrm{~W} / \mathrm{m}^{2} \mathrm{~K}$. The last term corresponds to the heat loss by radiation; $\sigma$ is the Stefan constant and the emissivity, $\varepsilon$, is taken as 0.7 . The fluid flow conditions on this face are:

$$
\mathrm{v}_{\mathrm{z}}=0 . \text { and } \overrightarrow{\tau_{n s}}=\frac{\partial \gamma}{\partial \mathrm{T}} \overrightarrow{\operatorname{gradT}}=-\mathrm{AgradT} \text { with } \mathrm{A}=-\frac{\partial \gamma}{\partial \mathrm{T}}
$$

where $\gamma$ is the surface tension, $\tau_{n s}$ the shear force applied on the fluid owing to the Marangoni effect and A the temperature dependence of $\gamma$. For CMSX4, A is set to $410^{-4} \mathrm{~N} / \mathrm{mK}$, which is the value for pure $\mathrm{Ni}$ at its melting temperature. It is thus necessary to refine the mesh close to the top surface in order to capture the velocity boundary layer that can be estimated as follows:

$$
\overrightarrow{\tau_{n s}}=-\mu \frac{\partial v}{\partial n} \text { and } \delta=\frac{\mu V_{s u f}}{A G}
$$

where $\mathrm{G}$ is the mean thermal gradient and $\mathrm{V}_{\text {surf }}$ the velocity at the surface. By taking $10^{5} \mathrm{~K} / \mathrm{m}$ and $1 \mathrm{~m} / \mathrm{sec}$ for these two quantities, the boundary layer $\delta$ becomes 25 microns. This particular boundary conditions is included in the fluid flow model with the help of volumetric momentum located on a very thin layer just under the top face of the computation domain and defined in some user functions. On the symmetry plane, the thermal boundary condition correspond to a zero heat flux conditions and to a zero y component of the flow velocity vector. At the "in" and "out" faces, a zero heat flux condition is also applied whereas a Cauchy condition is applied an all the remaining faces with a heat transfer coefficient of $50 \mathrm{~W} / \mathrm{m} 2 \mathrm{~K}$ and an external temperature of $20^{\circ} \mathrm{C}$.

\subsection{Computation strategy}

The computation consists first in running a thermal calculation only during a few seconds in order to get a pseudo steady state thermal field. Then the fluid flow solver is activated and 100 steps of $0.1 \mathrm{~ms}$ each are run to get the final steady state.

\section{RESULTS AND DISCUSSION}

The computed results are presented hereafter for the scanning speed of $5 \mathrm{~mm} / \mathrm{sec}$ with and without inclusion of the Marangoni convection. Then, the influence of changing the scanning speed on the laser traces is presented while the laser power remains the same, i.e. with a constant interaction time. Laser power and diameter are kept to $1700 \mathrm{~W}$ and $2 \mathrm{~mm}$ respectively.

\subsection{Natural and Marangoni convection $(\mathrm{V}=5 \mathrm{~mm} / \mathrm{sec})$}

Fig. 6 shows the computed liquid pool and flow field when only natural convection (buoancy) is taken into account. The centre of the laser beam, $2 \mathrm{~mm}$ in diameter, and its periphery are also shown. The temperature distribution on the top surface is shifted to the right owing to the laser speed. The natural 

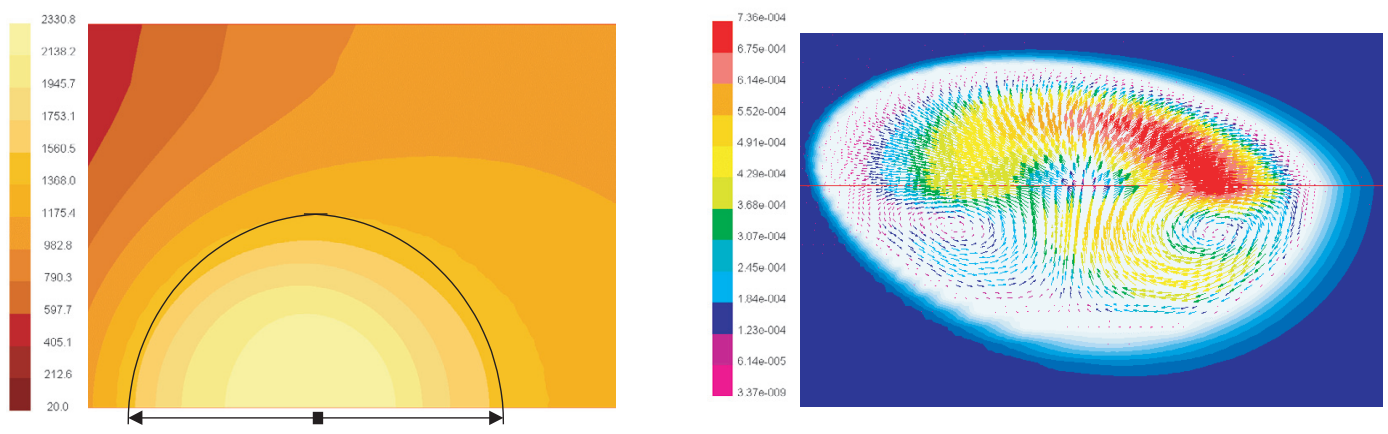

Figure 6. Temperature distribution on the top surface (natural convection only, left) and velocity distribution over the liquid pool (right) $(\mathrm{V}=5 \mathrm{~mm} / \mathrm{sec}$, Power $=1700 \mathrm{~W}$, diameter $=2 \mathrm{~mm})$.
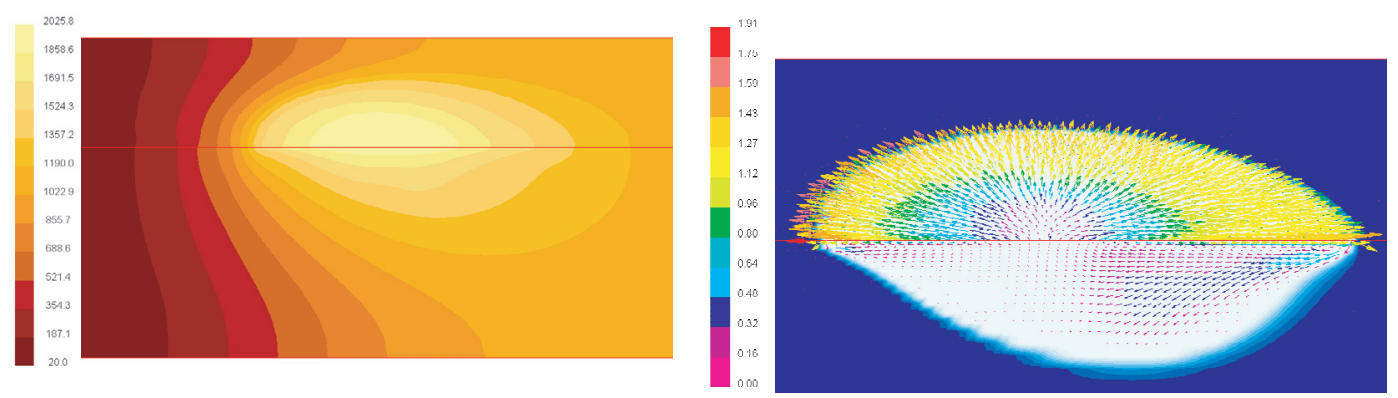

Figure 7. Temperature distribution (Marangoni and natural convection, left) and velocity distribution over the liquid pool (right) $(\mathrm{V}=5 \mathrm{~mm} / \mathrm{sec}$, Power $=1700 \mathrm{~W}$, diameter $=2 \mathrm{~mm})$.

convection creates classic eddies but one should notice that the velocity remains very low, lower than 1 $\mathrm{mm} / \mathrm{sec}$.

Fig. 7 shows the computed liquid pool and flow field when Marangoni convection is taken into account in addition to natural convection, the scanning speed being kept to $5 \mathrm{~mm} / \mathrm{sec}$. The temperature distribution is distorted by the liquid flow induced by the Marangoni convection which now gives rise to velocities of the order of $1 \mathrm{~m} / \mathrm{sec}$, about 1000 times higher than with natural convection. The shape of the liquid pool is also affected by the convection : it widens both in the transverse and longitudinal planes. In Fig. 8, the different views clearly show the development of eddies associated to large surface thermal gradient at the periphery of the laser beam.

\subsection{Influence of the scanning speed on laser traces}

With the help of a routine specially designed for the post-processing of the computed results, the trace of the laser, i.e. the position of the iso-liquidus surface can be retrieved together with the values of the thermal gradient $\mathrm{G}$ and the solidification speed V. The traces are shown in Fig. 9 for two different scanning speeds, 5 and $15 \mathrm{~mm} / \mathrm{sec}$. At $5 \mathrm{~mm} / \mathrm{sec}$, the case without Marangoni effect (natural convection only) is also reported. The scattering of the points is due to the mesh density that reduces when going downwards (see mesh in Fig.5).

It appears that as the speed decreases from 15 to $5 \mathrm{~mm} / \mathrm{sec}$, the liquid pool gets bigger than the laser beam extension thus giving birth to strong Marangoni eddies induced at the periphery of the laser beam $(y=1 \mathrm{~mm})$ where thermal gradients and therefore surface tension gradients are maximum. These 


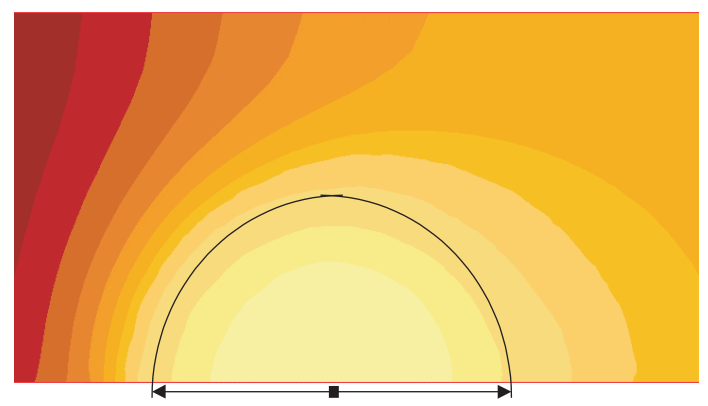

temperature field, top view (scale in Fig.7)

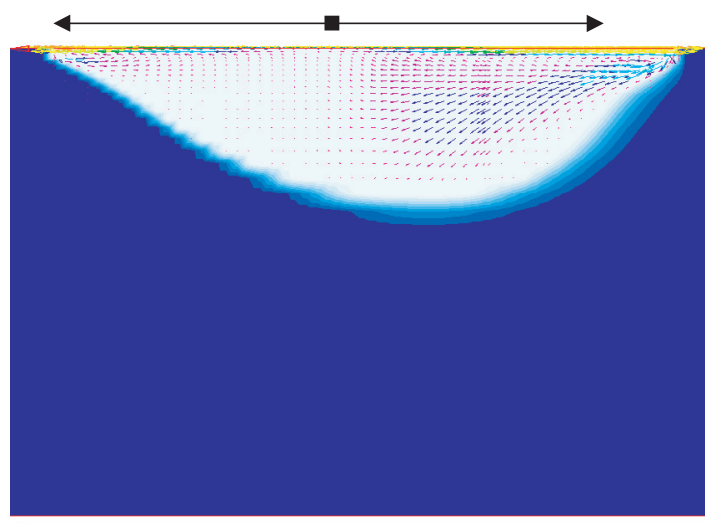

flow field, longitudinal section

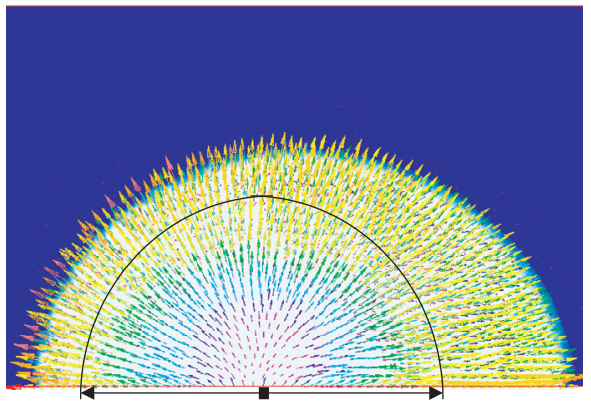

flow field, top view

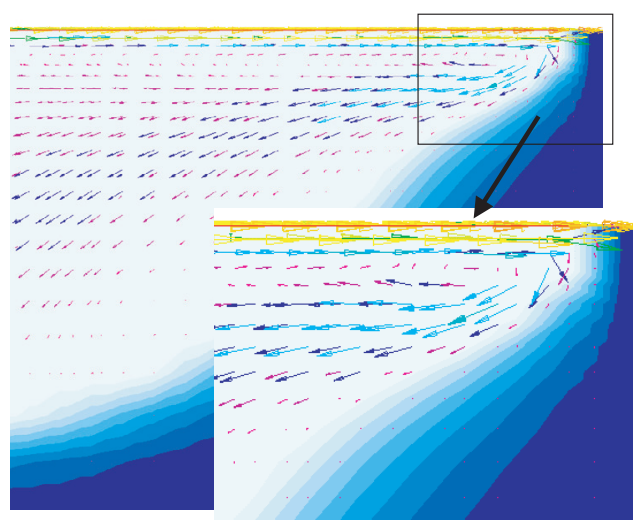

flow field, detail of the eddy at rear

Figure 8. Computed results when taking into account the Marangoni convection in the liquid pool $(\mathrm{V}=5 \mathrm{~mm} / \mathrm{sec}$, Power $=1700 \mathrm{~W}$, dia. $=2 \mathrm{~mm}$ ). The extension of the laser beam is shown.

eddies largely influence both the temperature and solid fraction fields. On the other hand, neglecting the Marangoni convection within the liquid pool leads to a rather different trace. Although the top liquid surface is assumed to stay flat, the results presented in Fig. 9 agree well with the trends reported in the experimental observations (section II).

\section{CONCLUSION}

The three dimensional finite element model implemented in calcosoft $($ allows us to compute the fluid convection within the liquid pool during laser re-melting. It appears that the velocities due to natural convection are of the order of $1 \mathrm{~mm} / \mathrm{sec}$ whereas Marangoni convection produces velocities of the order of $1 \mathrm{~m} / \mathrm{sec}$. Moreover, at low scanning speeds, the liquid pool becomes larger than the beam diameter if sufficient power is applied, and the development of Marangoni eddies leads to a widening and deepening of the pool. When the scanning speed increases, the transverse eddies disappear whereas those in the longitudinal plan get bigger. With the help of a routine specially designed for the post-processing of the computed results, the trace of the laser, i.e. the position of the iso-liquidus surface can be retrieved together with the values of the thermal gradient $\mathrm{G}$ and the solidification speed $\mathrm{V}$. The computed traces agree with the trends measured in laser re-melting experiments. The next steps will consist in computing 


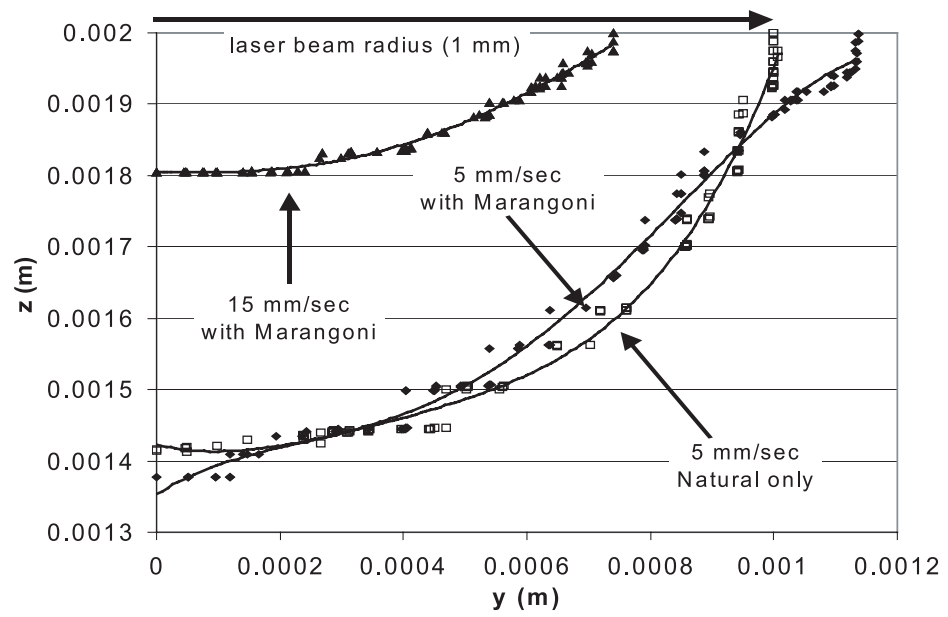

Figure 9. Computed laser traces for two scanning speeds $($ Power $=1700 \mathrm{~W}$, diameter $=$ $2 \mathrm{~mm})$.

the dendrite growth velocity in the crystallographic frame [12] and in including in the model CET and hot cracking criteria.

\section{Acknowledgements}

This work has been performed within the frame of the EU project AWFORS, Advanced welding technologies for repair and salvage of high valued engine components on nickel and titanium based alloys, in collaboration with Rolls-Royce Deutschland GmbH, Turbomeca SA, Ecole Polytechnique Federale de Lausanne, ELASIS - Sistema Ricerca Nel Mezzogiorno ScpA, Sulzer Innotec AG, Rheinisch-Westfaelische Technische Hochschule Aachen, ENEA - Ente per le Nuove Technologie, l'Energia e l'Ambiente, Lombardini F.I.M. Srl, Groupement d'étude et de recherche pour les applications industrielles des laser de puissance, Universita degli Studi di Lecce and MTU Motoren- und Turbinen-Union Munchen GmbH. This project concentrates on an integrated repair technology for blade repair, focussing on two part families (BLISK blades with 3D blading, HPT blades) and two basic weld repair technologies (Laser Cladding -LC and Capacity discharge welding - CDW).

\section{References}

[1] M. Gäumann, H. Rusterholz, R. Baumnann, J.-D Wagnière and W. Kurz, Materials for Advanced Power Engineering 1998, J. Lecomte-Beckeers et al. (eds.), Germany, 1998

[2] J.-M. Drezet, M. Gäumann, O. Greim and M. Gremaud: A Thermo-mechanical model of the epitaxial laser metal forming process, in MCWASP IX, Eds. Sahm, Hansen Conley, Shaker Verlag, Aachen 2000, 806-813.

[3] M. Gäumann, C. Bezençon, P. Canalis and W. Kurz. Acta mater.vol.49, 2001 pp. 1051-1062.

[4] M. Rappaz, J.-M. Drezet and M. Gremaud: "A New Hot Tearing Criterium", Met. Trans., vol. 30A, Feb. 1999, p. 449.

[5] D. Rosenthal, Trans. ASME 11 (1946), p. 849.

[6] A. F. A Hoadley. M. Rappaz and M. Zimmermann, Met. Trans., 22B, Feb. 1991, p. 101-109.

[7] C. Chan, J. Mazunder and M. M. Chen: Met. Trans., 15A, Dec. 1984, p. 2175-2184.

[8] C. Limmaneevichitr and S. Kou, Welding research supplement, May 2000, p. 126-135 and August 2000, p. 231-237.

[9] calcosoft $^{\mathbb{R}}$, user manual, Calcom SA, ref9 http://www.calcom.ch, CH-1015 Lausanne, Switzerland.

[10] A. Hauert, semester work at CTML, EPF-Lausanne, June 2002.

[11] S. Mokadem, diploma work at CTML, EPF-Lausanne, March 2001.

[12] M. Rappaz, S. A. David, J. M. Vitek and L. A. Boatner, Met. Trans., 20A, June 1989, p. 1125-1138. 